\title{
新疆吐鲁番坳陷连木沁剖面陆相白严一 第三系界线灾变事件初步研究
}

\author{
钟笁春 唐文松 赵秀兰徐道一 严 正叶莲芳 \\ (石油勘探开发科学研究院, 北京 100083）（圂家地震局地质研究所, 北方 100029） \\ 毛雪 愥 \\ (中国科学院高能物理研究所, 北京 100080)
}

\section{关链词白严系一第三系界线、碳同位素、银异常、灾变事件}

白严纪采期、地球上发生过全球性的生物绝灭. 1980 年 Alvarey 等 ${ }^{[1]}$ 在意大利、西班牙 等地海相白严-第三系 ( $\mathrm{K}-\mathrm{R}$ ) 界线层中发现了铱异常, 至今全球已在几十个地点包括我国西 藏地区都有类似的发现 ${ }^{[2]}$. 1981 年 Orth 等 $^{[3]}$ 又在美国新墨西哥州北部的 Raton 盆地陆相 $\mathrm{K}-\mathrm{R}$ 界线层中也发现了铱异常.

我国陆相白严系与第三系虽广布于各含油气盆地中,但存在白严-第三系 (K-R) 界线地 层的剖面大多为红色沉积, 因此有关 $K-R$ 界线划分和灾变事件的研究论文尚不多. 1983 年 以来, 中国科学院和德国的地质古生物工作者联合组队研究南雄盆地 $\mathrm{K}-\mathrm{R}$ 界线剖面, 取得了 古地磁、恐龙蛋结构及稳定同位素方面的一些重要结果 ${ }^{[4]}$. 1987 年中国石油天然气总公司组 织的全国油气区第三系研究, 对塔里木盆地西部海相 $\mathrm{K}-\mathrm{R}$ 界线的研究取得了较好的成果 ${ }^{[5,6]}$. 同时于 1989、1990 年两次赴吐鲁番坳陷进行野外考察 ${ }^{1)}$. 通过室内样品分析,首次在我国陆相 $\mathrm{K}-\mathrm{R}$ 界线层中发现碳同位素和铱异常.

\section{1 吐魯番坳陷连木沁 $\mathrm{K}-\mathrm{R}$ 界线剖面概况}

吐鲁番坳陷第三系分布广泛, 最大厚度 $2500 \mathrm{~m}$. 下第三系最早由新疆石油管理局命名为 缮善群, 它与白严系库穆塔克组之间为不整合接触. 60 年代中期翟人杰等 ${ }^{[7]}$ 根据在连木沁、胜 金口等地剖面中发现的脊椎动物化石, 将部善群的中下部划归晚白严世, 称为苏巴什组, 而将 其中上部定为古新世, 称为台子村组. 鄯善群上部为始新世巴坎组, 不属本文涉及范围. 苏巴 什组与台子村组之间为假整合接触, 其岩性自下而上为:

苏巴什组: 上部为一套灰红、砖红色砂岩夹泥岩, 含脊椎动物化石 Tyrannosaurus sp.; 中部为 砖红色泥质砂岩, 咖啡色砂质泥岩; 下部为棕红色砂砾岩, 含镈质结核. 本组顶部有 $1 \mathrm{~m}$ 多咖啡色泥 岩, 产 Shanshanosaurus houyanshanensis. 厚约 $150 \mathrm{~m}$.

台子村组: 上部为一套棕红、灰紫色泥岩、砂质泥岩夹砂岩, 含钻质结核, 顶部有薄层泥灰岩;

1992-05-04 收稿, 1992-09-22 收修改稿.

1) 参加野外考察的还有中国石油天然气总公司王仪诚。关学婷、郭橑杰、梁世君、王发泰,中国科学院古举椎动物与古人 类研究所谙永生. 
下部为灰黄、灰白色中-粗粒砂岩夹泥岩, 底部地层含脊椎动物化石 Psendictops chaii, Tienshanilophus lianmuainensis. Prodinoceras diconicus, Dilambda speciosa, Archaeolambda cf. planicanina 等, 最底部有砾状粗砂岩. 厚约 $52 \mathrm{~m}$.

由于上述划分从岩性及接触关系不如原划分方案明显,故有些野外地质工作者末能接受.

\section{2 分 析 结 果}

为进一步落实 $\mathrm{K}-\mathrm{R}$ 界线,我们在连木沁剖面(图 1)再次采集孢粉样品, 并按脊椎动物化 石划分的白严系与古新统，在其间未发现化石的 $5.7 \mathrm{~m}$ 地层段中重点采样. 在界线以上 $6 \mathrm{~m}$ 的 台子村组及以下 $3.7 \mathrm{~m}$ 的苏巴什组地层中共采样 30 块, 进行碳稳定同位素及铱等元素分析。

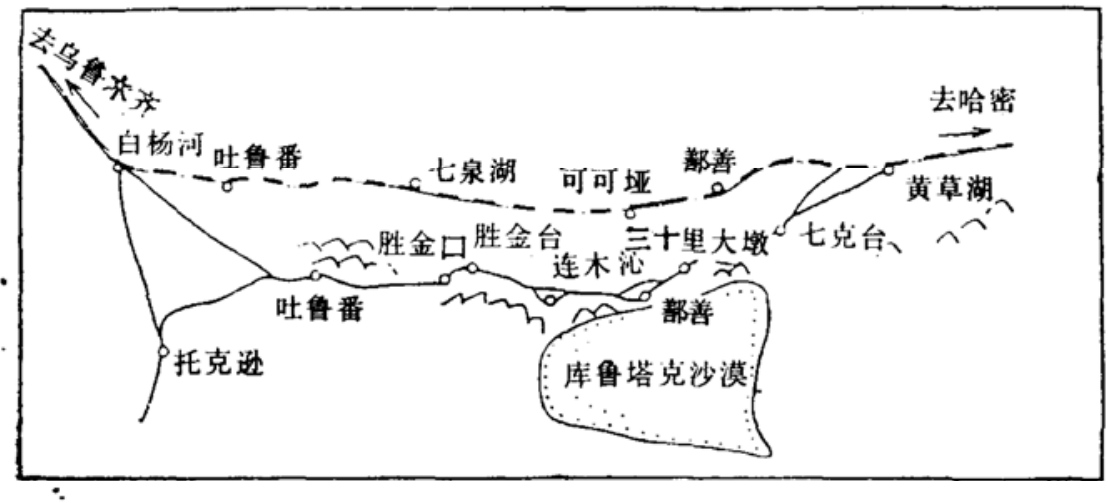

图 1 吐鲁番坳陷交通位置图

\section{1 狍粉化石}

在苏巴什组上部主要含 Schizaeoisporites, Deltoidospora, Classopollis annulatus, Pinuspollenites, Podocarpidites, Quercoidites, Ulmipollenites minor 等,时代为晚白严世.

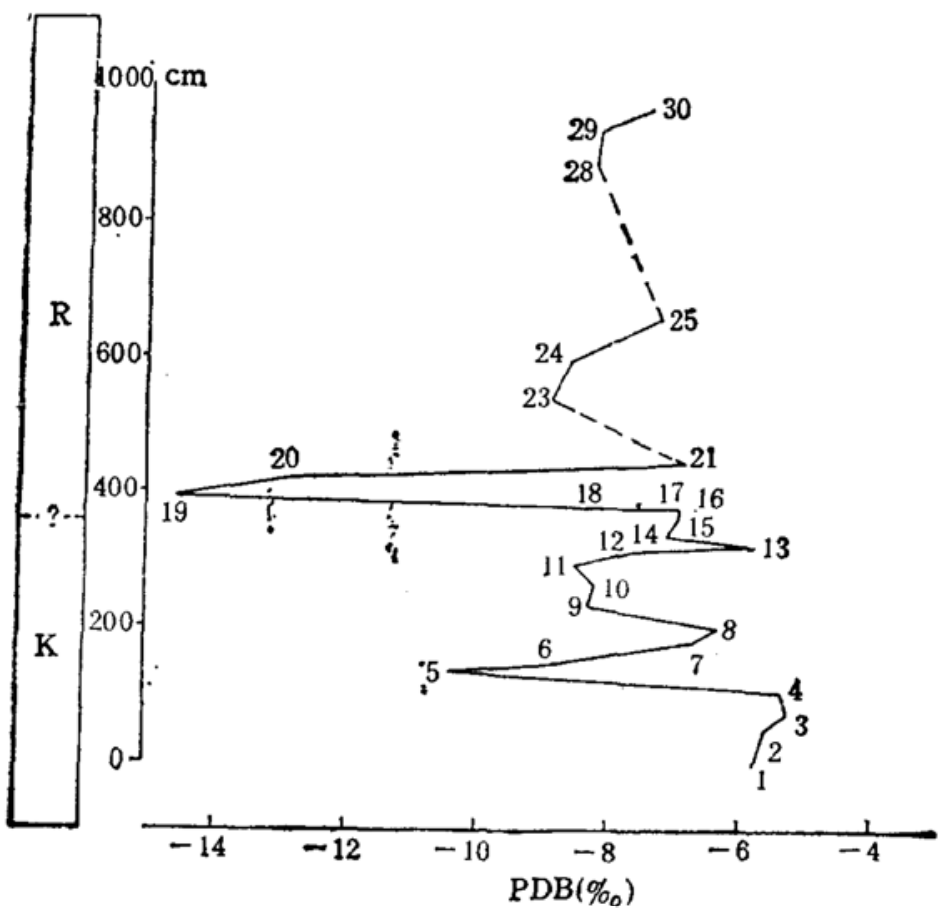

图 2 连木就剖面 $\mathrm{K}-\mathrm{R}$ 界线附近碳稳定同位素分布 
台子村组下部含 Pterisisporites, Lycopodiumsporites, Pinuspollenites, Podocarpidites, Taxodiaceaepollenites, Ephedripites, Quercoidites, Cupuliferoipollenites, Ulmipollenites, Betulaepollenites 等,时代为古新一始新世.

\section{2 碳稳定同位素}

将所采样品在室内作净化处理, 用磷酸法作碳同位素分析 ${ }^{[8]}$, 分析精度优于 $\pm 0.1 \% 0(2 \sigma)$, 其结果见图 2.

连木沁 $\mathrm{K}-\mathrm{R}$ 界线剖面所有样品碳稳定同位素组成均为负值, 平均 $\delta^{13} \mathrm{C}$ 为 $-8 \%$ 左右, 意味着白严系与第三系均为淡水相沉积环境, 但在碳同位素组成分布曲线上出现了明显的异 常峰, 最大负异常幅度为 $\delta^{13} \mathrm{C}$ 变化 $6 \%$ 左右, 刚好出现在按脊椎动物化石所划分的白严系顶 端, 古新世台子村组底部. 该异常经历时间短, 是碳同位素负异常事件, 反映了环境发生了很 大变化, 在这事件发生后不久,环境又恢复到原来状态, 从而碳同位素组成也回复到事件以前 的组成. 因此, $\delta^{13} \mathrm{C}$ 组成的变化可以作为地层界线划分的依据.

\section{3 铱及其它微贯元塞}

根据碳稳定同位素分布的分析结果,进一步选了 23 块标本进行仪器中子活化分析, 标本 经预处理后,放人中国原子能科学院核反应堆中照射 $16 \mathrm{~h}$ 后. 由中国科学院高能物理所毛雪瑛 等在同轴 $\mathrm{Ce}(\mathrm{Li})$ 探测器系统中测定了金等 32 种元素(包括 8 个稀土元素). 为了准确的测 定铱含量,又选了 11 块标本在反应堆中照射 $48 \mathrm{~h}$, 进行放化中子活化分析.

2.3.1 铱 由表 1 所列铱含量的分析结果可见, 铱的异常值分布在约 $60 \mathrm{~cm}$ 的岩层中, 最大含 量为 $0.2 \mathrm{ppb}$ 左右, 比铱的测量本底值高出约 20 倍, 测量误差不大, 因此,结果是可信的.

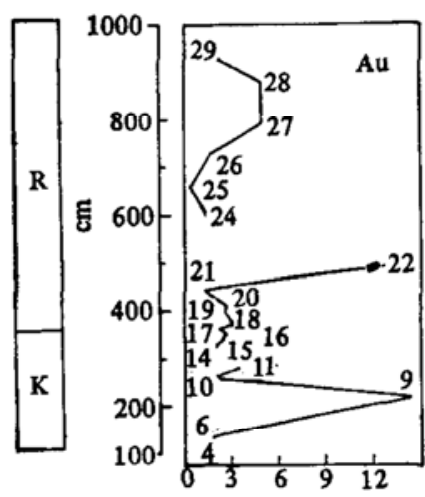

含重 (ppb)

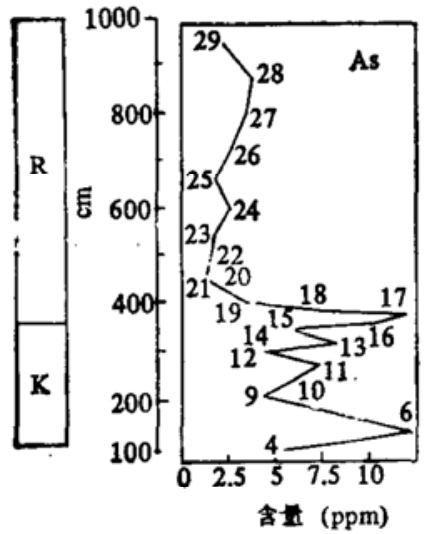

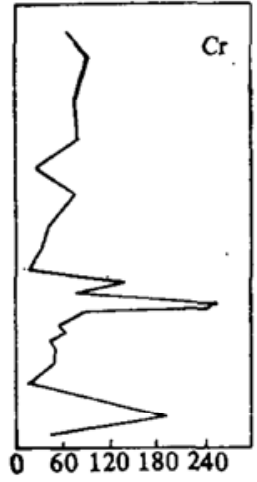

含量 $(\mathrm{ppm})$

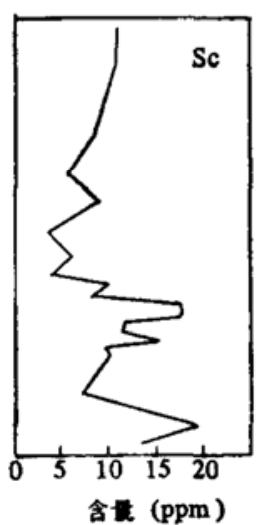

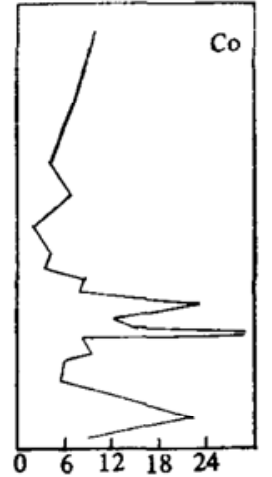

含量 (ppm)

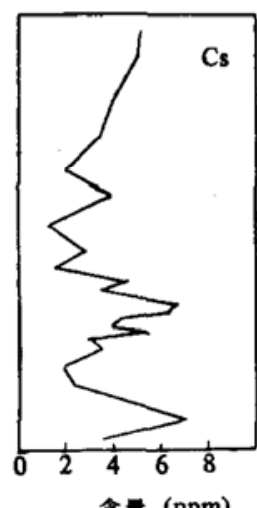

令量 $(\mathrm{ppm})$

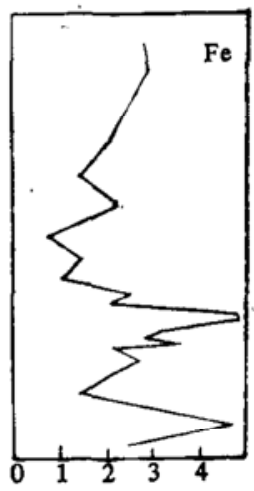

含量 (\%)

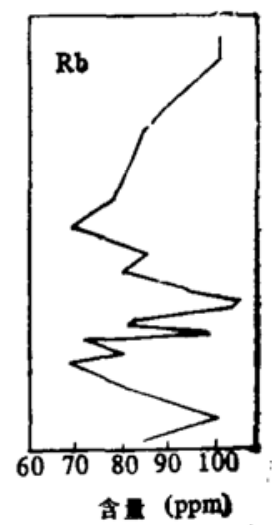

图 3 连木沁剖面 $\mathrm{K}-\mathrm{R}$ 界线地层元素变化曲线 
表 1 连木沁剖面 $\mathrm{K}-\mathrm{R}$ 界线地层 RNAA 分析结果

\begin{tabular}{|c|c|c|c|c|c|c|c|c|c|c|c|}
\hline 标本号 & L-29 & $\mathrm{L}-21$ & $\mathrm{~L}-20$ & L-19 & $\mathrm{L}-18$ & $L-17$ & $L-16$ & L-15 & L-14 & $L-13$ & L-12 \\
\hline $\begin{array}{l}\text { Ir 含量 } \\
\left.(\mathrm{ppb})^{2}\right)\end{array}$ & $<67$ & $<42$ & $<59$ & $<42.6$ & $\begin{array}{l}175 \pm \\
29.2 \%\end{array}$ & $\begin{array}{l}187 \pm \\
39.7 \%\end{array}$ & $<91$ & $\begin{array}{l}66.5 \pm \\
36.3 \%\end{array}$ & $\begin{array}{r}84.8 \pm \\
9.7 \%\end{array}$ & $\begin{array}{r}203 t \\
19.7 \%\end{array}$ & $<30$ \\
\hline
\end{tabular}

a) $1 \mathrm{ppt}$ 相当于 $10^{-t 2} \mathrm{~g} / \mathrm{g}, 1 \mathrm{ppb}=1000 \mathrm{ppt}$, 铱的本底值 $<9.96 \mathrm{ppt}$.

2.3.2 镍、铬等元素 图 3 所示为 $\mathrm{Au}, \mathrm{Cr}, \mathrm{Co}, \mathrm{Fe}$ 等元素在连木沁 $\mathrm{K}-\mathrm{R}$ 界线剖面含量的变 化曲线. 可见 $\mathrm{Cr}, \mathrm{Co}, \mathrm{Fe}, \mathrm{As}$ 等元素在 $\mathrm{L}_{13}-\mathrm{L}_{18}$ 层位处都有一个明显的峰值, 自 $\mathrm{L}_{1}$, 往上, 变 化幅度相对变小。

2.3.3 稀土元素 测定了 $\mathrm{La}, \mathrm{Ce}, \mathrm{Nd}, \mathrm{Sm}, \mathrm{Eu}, \mathrm{Tb}, \mathrm{Yb}, \mathrm{Lb}$ 等含量, 几乎所有稀土元素含致 标本 $\mathrm{L}_{13}-\mathrm{L}_{18}$ 中都出现了含量增加的明显变化. $\mathrm{La}, \mathrm{Ce}, \mathrm{Yb}$ 和 $\Sigma \mathrm{REE}$ 四条明线明显峰值所 在位置与 $\mathrm{Fe}, \mathrm{Cr}, \mathrm{Co}$ 等的曲线相似.

\section{3 讨 论}

（1）在没有化石的约 $6 \mathrm{~m}$ 岩层中, 发现了 $\delta^{13} \mathrm{C}$ 负异常, 中等程度的铱异常和多种微量元 素含量的变化. 和国外海相及陆相 $\mathrm{K}-\mathrm{R}$ 界线层中所发现的相比, 情况是相似的. 为此认为在 连木沁剖面中存在 $\mathrm{K}-\mathrm{R}$ 界线.

(2) 连木沁剖面 $\mathrm{K}-\mathrm{R}$ 界线具体划分的位置, 根据古生物化石的分布、 $\delta^{13} \mathrm{C}$ 负异常、 Ir 含量及其它微量元素的峰值等综合考虑, 认为在标本 $\mathrm{L}_{15}$ 与 $\mathrm{L}_{16}$ 之间较为合适, 它与翟人杰 等在野外划分的界线相差约 $10 \mathrm{~cm}$.

(3) 要提出的是 $\mathrm{Ir}$ 含皇在标本 $\mathrm{L}_{13}$ 也有 $0.2 \mathrm{ppb}$, 还䍏不少元素在 $\mathrm{L}_{13}$ 位置也出现了明 显变化. 由于野外采样密度不够, 我们的工作还是初步的, 因此, 上述情况的出现目前还难以 给予确切的解释.

通过吐鲁番坳陷连木沁剖面的研究工作，在我国陆相 $\mathrm{K}-\mathrm{R}$ 界线层中首次发现了铱等元 素异常的存在,它为证明铱异常全球性的分布增添了实例,同时也为海、陆相 $\mathrm{K}-\mathrm{R}$ 界线准确 的洲际对比提供了可靠依据. 因此,有必要进一步的深人研究.

\section{参考文献}

[1] Alvarez, L. W. et al., Science, 1980, 208: 1095-1108.

[2] Xu Dao-yi et al., Astrogeological Events in China, Geological Publishing House, Beijing, 1989; Van Nostrand Reinhold, New York; Scottish Acadimic Press, Edinburgh, UK, 264.

[3] Orth, C. J. et al., Science, 1981, 214: 1341-1343.

[4] 赵资牵、叶捷、李华梅等,古脊椎动物学报, 1991,29(1): 1-20.

[ 5 ] 叶得泉等,石油学报, $1992,(2): 202-208$.

[6]唐文松、钟花春等,石油学报,1992,(2): 209-214.

[7] 翟人杰、郑家坚、童永生, 新疆吐鲁番盆地第三纪地层,中国科学院古脊椎动物与古人类研究所甲种专刊, 第十三号, 科学出版社,北京, 1978: 68-81.

[8]严正、叶莲芳,东海海洋, 1983,1(4): 40-44。 